\title{
Carvedilol was more effective than metoprolol tartrate for lowering mortality in chronic heart failure
}

Poole-Wilson PA, Swedberg K, Cleland JG, et al. Comparison of carvedilol and metoprolol on clinical outcomes in patients with chronic heart failure in the Carvedilol Or Metoprolol European Trial (COMET): randomised controlled trial. Lancet 2003;362:7-13.

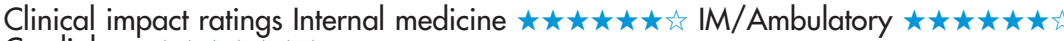
Cardiology $\star \star \star \star \star \star \star \star \star \lambda / 2$

In patients with chronic heart failure (CHF), what is the comparative effectiveness of carvedilol and metoprolol tartrate on morbidity and mortality?

METHODS

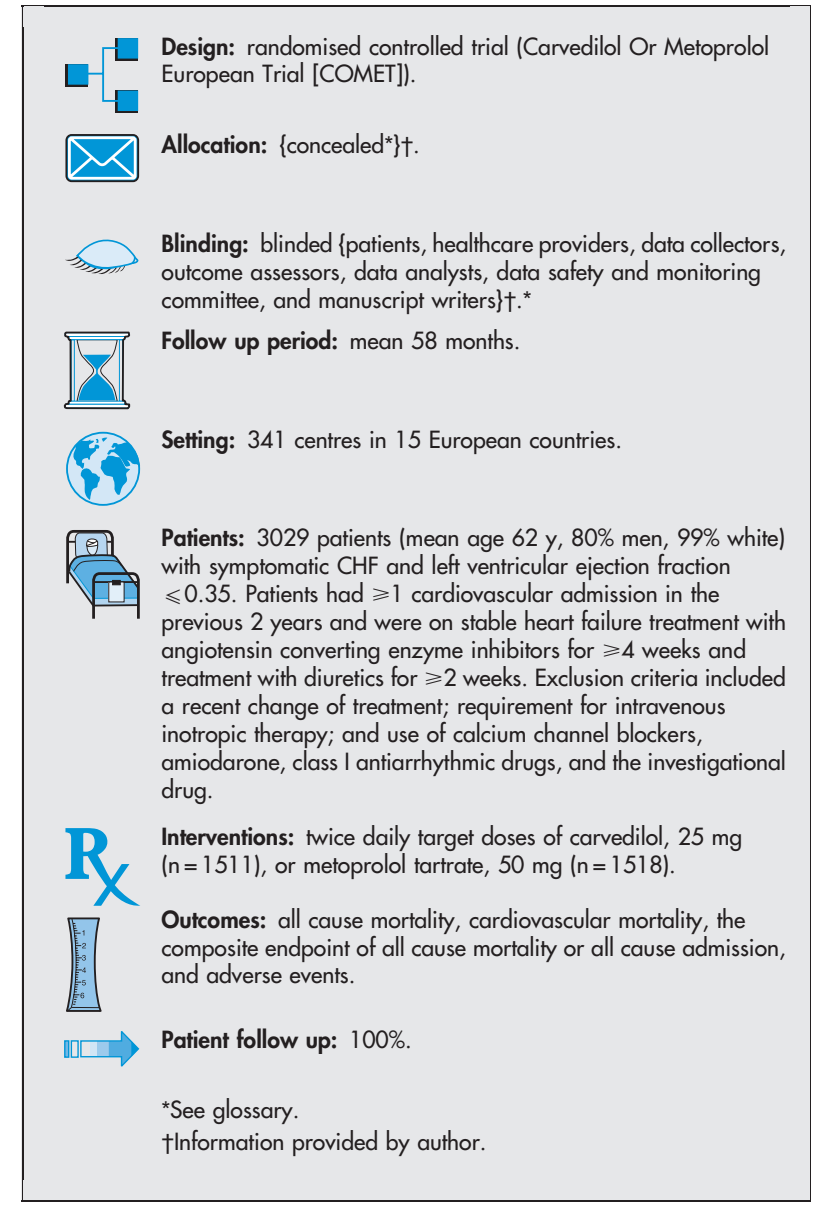

MAIN RESULTS

Analysis was by intention to treat. Patients who received carvedilol had lower risks of all cause mortality and cardiovascular mortality than did those who received metoprolol tartrate; however, the carvedilol and metoprolol tartrate groups did not differ for the composite endpoint of all cause mortality or all cause admission, or for non-cardiovascular mortality (table). Groups did not differ for adverse events.

\section{CONCLUSION}

In patients with chronic heart failure, carvedilol was more effective than metoprolol tartrate for lowering all cause mortality and cardiovascular mortality.

\section{Abstract and commentary also appear in ACP Journal Club}

For correspondence. Professor P A Poole-Wilson, National Heart and lung Institute, London, UK. p.poole-wilson@imperial.ac.uk

Sources of funding: F Hoffman La Roche and GlaxoSmithKline.
Carvedilol $v$ metoprolol tartrate in chronic heart failure at mean 58 months*

\begin{tabular}{|c|c|c|c|c|}
\hline Outcomes & Carvedilol & $\begin{array}{l}\text { Metoprolol } \\
\text { tartrate }\end{array}$ & $\operatorname{RRR}(95 \% \mathrm{Cl})$ & NNT (Cl) \\
\hline All cause mortality & $34 \%$ & $40 \%$ & $14 \%(5$ to 21$)$ & $19(12$ to 46$)$ \\
\hline $\begin{array}{l}\text { Cardiovascular } \\
\text { mortality }\end{array}$ & $29 \%$ & $35 \%$ & $17 \%$ (8 to 26$)$ & $15(10$ to 31$)$ \\
\hline $\begin{array}{l}\text { All cause mortality } \\
\text { or all cause } \\
\text { admission }\end{array}$ & $74 \%$ & $76 \%$ & $3 \%(-0.9$ to 7$)$ & Not significant \\
\hline $\begin{array}{l}\text { Non-cardiovascular } \\
\text { mortality }\end{array}$ & $5 \%$ & $4 \%$ & $\begin{array}{l}\text { RRI (CI) } \\
6 \%(-19 \text { to } 34)\end{array}$ & $\begin{array}{l}\text { NNH } \\
\text { Not significant }\end{array}$ \\
\hline
\end{tabular}

*Abbreviations defined in glossary; RRR, RRI, NNT, NNH, and Cl calculated from data in article using Cox proportional hazards ratio.

\section{Commentory}

hanks to the remarkable successes in drug development, a variety of effective treatments are available for most medical conditions. The

new challenge is often how to select the optimal therapy. For approval purposes, regulatory agencies require placebo controlled rather than active comparison trials. The federally funded ALLHAT represents an important comparative trial of antihypertensives. ${ }^{1}$ A recently introduced congressional bill calls for more ALLHAT-like comparative trials. ${ }^{2}$ The financial implications are enormous.

The treatment of $\mathrm{CHF}$ is a crowded field with multiple choices, both between and within drug classes. In placebo controlled trials in heart failure patients, carvedilol and metoprolol CR/XL reduce mortality to a similar extent. Thus, an indirect comparison suggests little or no difference between drugs.

The findings of COMET, sponsored by the manufacturer of carvedilol, contradict this expectation, and the investigators conclude that carvedilol extends survival more so than metoprolol. Alternative explanations are possible. The target dose for carvedilol in COMET was the Food and Drug Administration recommended dose of $25 \mathrm{mg}$ twice daily. The investigators used metoprolol tartrate $50 \mathrm{mg}$ twice daily, which is not approved for heart failure. The metoprolol dose in COMET was also less than the approved long acting formulation, metoprolol CR/XL $200 \mathrm{mg}$ daily (equivalent to $130 \mathrm{mg}$ metoprolol tartrate). Mean reductions in heart rate and systolic blood pressure in COMET support the view that the $\beta$ blocking effect of the metoprolol dose was less pronounced than that of the carvedilol dose. An editorial by Dargie ${ }^{3}$ raised the issue of comparable $\beta$ blockade. These and other inconsistencies suggest that the results of COMET are not definitive.

Proper trial design is essential to interpretation of comparative trials. Independence from pharmaceutical sponsors may be important to avoid suboptimal comparators, suboptimal doses, or suboptimal formulations. Curt D Furberg, MD, PhD Wake Forest University School of Medicine Winston-Salem, North Carolina, USA Bruce M Psaty, MD, PhD University of Washington Seattle, Washington, USA

1 Major outcomes in high-risk hypertensive patients randomized to angiotensin-converting enzyme inhibitor or calcium channel blocker vs diuretic: The Antihypertensive and Lipid-Lowering Treatment to Preven Heart Attack Trial (ALLHAT). JAMA 2002;288:2981-97.

2 Comparing Prescription Drugs. New York Times, August 27, 2003. www.nytimes.com/2003/08/27/opinion/27WED3.html

3 Dargie HJ. Beta blockers in heart failure. Lancet 2003;362:2-3. 